\title{
Designer Estratégico Como Operador Social: Reflexões Acerca de Um Cenário Metaprojetual
}

\author{
Strategic Designer as a Social Operator: Reflections on a Metaprojectual Scenario
}

COSTA, Filipe C. X.; Doutor; Programa de Pós Graduação em Design, UNISINOS

fcampelo@unisinos.br

FRANZATO, Carlo; Doutor; Programa de Pós Graduação em Design, UNISINOS

cfranzato@unisinos.br

SANT'ANNA, Paula A. G.; Mestranda; Programa de Pós Graduação em Design, UNISINOS

paula@inch.com.br

\section{Resumo}

O campo do design avança do interesse nas habilidades técnicas do designer ao desenvolvimento de sua capacidade crítico-reflexiva quanto ao papel social da profissão. Nesse sentido, o design estratégico desenvolve as estratégias que fundamentam a ação projetual, orientado pela inovação e sustentabilidade, atuando em nível metaprojetual. Em paralelo, motiva-se a geração de abordagens hipotéticas que provoquem a reflexão acerca de uma visão plausível e discutível compreendida aqui como cenário. A partir de uma aproximação metaprojetual, este artigo propõe um cenário design-orienting (DOS) no qual o designer estratégico atua, e assim é reconhecido, como um operador social, isto é, um ator ecossistêmico que explora seu potencial criativo, técnico e estratégico com o principal objetivo de propor soluções que beneficiem a sociedade. Essa capacidade e pressuposto, fundamentados na reflexão crítica aplicada a todos os contextos com os quais trabalha, orientam permanentemente a atuação do designer.

Palavras Chave: design estratégico; metaprojeto; cenário.

\begin{abstract}
The field of design advances from the interest in the technical skills of the designer to the development of his critical-reflective capacity as to the social role of the occupation. In this sense, the strategic design develops the strategies that justify the project action, guided by innovation and sustainability, acting at the metaprojectual level. In parallel, hypothetical approaches are motivated to provoke the reflection about a plausible and debatable vision. From a metaprojectual approach, this article proposes a design-orienting scenario (DOS) in which the strategic designer acts, and thus is socially recognized, as a social operator, that is, an ecosystemic actor that exploits his creative, technical and strategic role with the main objective of proposing solutions for a collectively harmonious and sustainable life. This capacity and assumption, based on the critical reflection applied to all the contexts with which it works, permanently guides the performance of this actor.
\end{abstract}

Keywords: strategic design; metaproject; scenario. 


\section{Introdução}

O design materializa-se em nossa rotina por meio de produtos, serviços e tecnologias, moldando grande parte das experiências vivenciadas pela sociedade. A utilização desses recursos, por sua vez, desempenha papel fundamental na mediação entre as pessoas, já que são capazes de provocar percepções, motivações, comportamentos e implicações a longo termo. Diversos filósofos e sociólogos já discutiram como os produtos afetam nosso comportamento e estrutura social sem que isso seja percebido (KRIPPENDORFF, 2005; LATOUR, 1992; SHOVE ET AL, 2007; VERBEEK, 2011).

De acordo com Tromp (2013), o ambiente projetado influencia a forma como os indivíduos vivem, agem e experienciam o mundo nas esferas física e social. Nessa compreensão, atenta-se às implicações sociais do design, motivando o surgimento de abordagens que investigam o potencial do design que ultrapassa o eixo técnico-projetual e explora sua capacidade de gerar impacto na sociedade. A partir do questionamento "Como o design pode contribuir para a solução de um determinado problema social?", Tromp (2013) estuda a influência do design no comportamento humano e propõe o método SID - Social Implication Design. Sua proposta é nortear ações projetuais que influenciem comportamentos individuais e coletivos com a finalidade de causar uma implicação social desejada, a qual deve amenizar ou encerrar o problema social analisado.

Problemas sociais para os quais não se encontre solução nos modelos econômicos tradicionais também são ponto de partida para estimular a inovação social (MANZINI, 2017). Em um mundo de crise político-econômica, essas inovações recombinam recursos e capacidades já existentes para criar novas funções e sentidos. Segundo Manzini (2017), elas introduzem maneiras de pensar e estratégias para resoluções de problemas que conseguem descontinuar o que é localmente predominante, causando, assim, a inovação. Ao envolver todos os atores do ecossistema social - organizações, universidades, indivíduos, famílias, comunidades - de maneira ativa e colaborativa, a inovação social torna-se um agente de mudança em potencial para o sistema sociotécnico.

No contexto da inovação social, emerge a modalidade do design com potencial para desempenhar um importante papel no desencadeamento e suporte à mudança social, configurando, assim, o design para inovação social (MANZINI, 2015). O termo refere-se a tudo o que o design especializado pode fazer para ativar, sustentar e orientar processos de mudança social na direção da sustentabilidade. Dessa maneira, ao dominar a esfera projetual e compreender suas possíveis implicações nas dinâmicas sociais, o designer se guarnece de uma alta capacidade de visualização e modificação de contextos:

\footnotetext{
Considerado como um operador que atua em relação ao ambiente diário, a responsabilidade final do designer só pode ser contribuir para a produção de um mundo habitável, um mundo em que os seres humanos não sobrevivem apenas, mas também expressam e expandem suas possibilidades culturais e espirituais. O termo habitável, referente ao ambiente, indica uma condição existencial complexa que não pode ser reduzida ao seu componente funcional. É uma condição decorrente da interseção de uma multiplicidade de questões enraizadas na natureza antropológica e social da raça humana. (MANZINI, 1992, p. 5).
}

Contribuir para a produção de um mundo habitável é algo que requer, entretanto, a expansão de seu escopo para a inclusão de especulação acerca das melhores maneiras para novas proposições (DUNNE, 2008). Segundo o autor, visualizar um mundo melhor não é suficiente; é 
necessário despertar na sociedade o desejo por um. Essa investigação exploratória torna-se possível nas realidades retratadas por meio de cenários alternativos. Para tanto, Dunne (2008) propõe a concepção de designs conceituais - não referenciando o estado conceitual de um projeto, mas um produto concebido com o objetivo de desafiar os conceitos prévios sobre como os artefatos moldam nossas vidas, em especial os eletrônicos. O desafio se estabelece na ruptura de barreiras entre o real e fictício, o confronto ao status quo, e o encorajamento à crítica reflexiva e mensuração de possibilidades frente ao artefato como incorporação de padrões de comportamento e ideologia.

Meroni (2008) corrobora com a relevância dos cenários para a sociedade futura. Segundo a autora, a geração de cenários no campo do design permite transformar visões em hipóteses plausíveis, por meio da projeção do que pode vir a acontecer dentro de premissas de previsibilidade. Essa forma de conjecturar situações futuras é, de acordo com Meroni (2008), uma das maneiras mais favoráveis de desenhar soluções criativas para a inovação social.

O desenvolvimento de cenários é também uma ferramenta de conversação estratégica, pois suas hipóteses podem facilitar um diálogo entre os atores sociais e desejavelmente gerar uma convergência de opiniões entre eles (MANZINI E JÉGOU, 2006). De acordo com os autores, cenários se materializam a partir da visão de um hipotético estado das coisas que alguém foi capaz de conceber e descrever de forma comunicável e compreensível. Sua geração permite desenvolver visões articuladas e motivadas que, se devidamente construídas e promovidas, podem vir a tornar-ser visões compartilhadas por todo o ecossistema social (empresas, instituições públicas e sociedade como um todo).

Na visão de Mazini e Jégou (2006), cenários devem ser plausíveis e discutíveis, ou seja, devem oferecer argumentos claros para discussão, sugerindo alternativas, pressupostos e justificativas. Eles são compostos de 1) Visão: componente que fundamenta o cenário, responde à questão "como seria o mundo se..." e propõe uma história sintética dos estado das coisas no contexto imaginado; 2) Motivação: componente que o legitima e dá sentido, responde à pergunta "por que esse cenário é significativo?" e explica racionalmente as premissas e condições consideradas; e 3) Propostas: componente que dá consistência a uma visão, responde às questões "Como é articulada a visão? Quais são seus elementos e como se pode implementá-la?".

Quando as visões são motivadas e articuladas com o objetivo de catalisar as energias de atores envolvidos no processo de design, configura-se um cenário design-orienting. Sua investigação possibilita explorar o campo do possível - possibilidades evolutivas do atual estado das coisas - com relação a um ou mais atores, assim como estabelecer uma discussão que favoreça a convergência de visões compartilhadas a partir de escolhas projetuais consistentes.

A partir da compreensão do iminente potencial do design em interferir positivamente às dinâmicas sociais, o presente artigo propõe um cenário design-orienting fundamentado na abordagem metaprojetual e aplicado em nível crítico-reflexivo à atuação do designer estratégico, profissional que agrega diversas habilidades convergentes ao escopo debatido. Como método, serão consideradas as diretrizes metaprojetuais, por possibilitarem um exercício que atua acima da ação projetual do design e que visa a reflexão crítica e melhoramento dos seus processos, aplicadas à revisão teórica apresentada. 


\section{Abordagem Metaprojetual no Design}

A evolução dos estudos em design coloca em pauta a crítica de temas como práticas de design e processos criativos. Um dos seus relevantes desdobramentos é o metaprojeto, processo que motiva a reflexão sobre os níveis de conhecimento do design, ponto de movimento do qual resultam as relações dinâmicas dos processos projetuais (BENTZ E FRANZATO, 2016). Os autores propõem que o design projetual, em seu caráter técnico, seja orientado por um nível superior, intitulado metaprojeto, capaz de exercer senso crítico-reflexivo sobre os processos que fundamentam a prática projetual e, assim, melhorá-la. Acima deste, estaria o nível metametaprojetual, capaz de gerar novos métodos de design e orientar a prática dos níveis abaixo. Por fim, o nível de superioridade seria o metametametaprojeto, do qual poderia derivar-se uma nova proposta epistemológica ao campo de estudo (BENTZ E FRANZATO, 2016).

Figura 1 - Proposta de design em relação aos níveis de conhecimento

\begin{tabular}{ll|l} 
EPISTEMOLÓGICO & (Meta Meta Meta) & $\begin{array}{l}\text { (Bases epistemológicas) } \\
\text { (Design Estratégico) }\end{array}$ \\
METODOLÓGICO & (Meta Meta) & $\begin{array}{l}\text { (Metadesign) } \\
\text { METALINGUÍSTICO }\end{array}$ \\
LÍNGUA-OBJETO & (X)ta) & (Design) \\
\hline REALIDADE & ("Res") & ("Res")
\end{tabular}

Fonte: adaptado de Bentz e Franzato (2016)

Esse deslocamento de níveis do design é fundamentado por Franzato (2014) ao apresentar o princípio do deslocamento, que compreende os processos criativos como resultantes de práticas metaprojetuais. Sendo assim, no momento em que se aplica a lógica metaprojetual ao design, não se altera a natureza do processo, e sim o nível e a matéria da ação projetual, o que repercute na alteração dos resultado (BENTZ E FRANZATO, 2016).

Para os fins propostos neste artigo, é importante destacar a contribuição do metaprojeto a nível de crítica reflexiva no campo do design. Morin (1999, p. 28) atenta à respeito da necessidade de "se refletir, reconhecer, situar, problematizar" todo o conhecimento, já que não haveria "nenhum conhecimento sem conhecimento do conhecimento". O interesse do metaprojeto nos aspectos transitório e mutável, nas possiblidades do que pode vir a ser e no hipotético constitui um exercício reflexivo e flexível que permite transformações e benefícios aos processos projetuais:

\footnotetext{
Pela natureza teórico-prática do design, porém, ressalta-se a importância de deslocamentos verticais que, no movimento de cima para baixo, permitam a conscientização sobre a prática e sua transformação, e que, no movimento de baixo para cima, permitam a fertilização da teoria e seu desenvolvimento. Este contínuo movimento nos dois sentidos permite a inovação do design e disso deriva a importância do princípio de deslocamento que conduz a dinâmica inovadora. (BENTZ E FRANZATO, 2016, p. 1427).
}

Assim, utiliza-se o metaprojeto como o instrumento de crítica e reflexão que motiva a concepção de um cenário design-orienting. O cenário tem por objetivo provocar a reflexão sobre o papel do designer na sociedade e, como ponto de partida, toma como referência as características do designer estratégico, ator que possui diversas habilidades contextualizadas à visão proposta. 


\section{A Relevância do Design Estratégico}

Atuante em uma perspectiva ecossistêmica, o design estratégico se concentra, segundo Bentz e Franzato (2016), "no estudo das estratégias de design para orientar a ação projetual e, sobretudo, a ação organizacional, em direção à inovação e à sustentabilidade". Essas estratégias são elaboradas em um processo que envolve todo o seu ecossistema de atuação: o meio organizacional (escritórios de design, empresas e demais organizações), o mercado, a sociedade e o meio ambiente. Dessa maneira, o processo de design desenvolve-se nas múltiplas relações instauradas em torno da ação projetual, gerando implicações metodológicas relevantes. Na figura 1, o design estratégico encontra-se no eixo metametaprojetual em virtude de seu potencial metodológico, que desloca-se do processo de design em si para o conjunto de relações que os ecossistemas desenvolvem.

As competências técnicas do design, conectadas com diversas áreas do conhecimento, transformam-se, assim, em plataforma transdisciplinar que facilita a convergência dos especialistas e demais atores que integram uma rede de colaboração. Bentz e Franzato (2016) compreendem que o design estratégico é capaz de configurar a forma, função, valor e sentido de organizações protagonizadas por pessoas, uma vez que compreende as diferenças dos contextos socioculturais, o potencial das tecnologias e das redes. Para os autores, o efeito mais significativo do design estratégico é a continua organização e reorganização das atividades desenvolvidas nesse ecossistema.

O design estratégico também é referenciado na literatura por outras características. Se percebe que, diante de um problema complexo, mal definido e passível de múltiplas interpretações, cada vez mais faz-se necessário repensar seu escopo antes de projetar para uma solução. Esta habilidade, a de redefinir o problema (o quê) antes de solucioná-lo (como) é característica do processo projetual do design estratégico, segundo Meroni (2008). Essa reformulação, de acordo com os parâmetros estratégicos mais adequados, consolida a prática do contra-brief (MERONI, 2008). Na maioria das vezes, definir o problema é mais complexo do que solucioná-lo, pois depende da validação do briefing e de interpretações que variam de acordo com o repertório associativo de cada ator envolvido no processo projetual.

Zurlo (2010) credita ao designer estratégico três capacidades: as de ver, prever e fazer ver. Ver diz respeito ao olhar crítico, curioso e livre de estereótipos sobre um problema. Prever agrega a visão criativa na projeção de cenários futuros, mesmo que mentais. Fazer ver possibilita a materialização das ideias através de protótipos e execução projetual. Segundo o autor, essas três características funcionais são fundamentais no processo estratégico. Contudo, é importante observar as dimensões subjetivas das escolhas. Ao distanciar-se do pressuposto objetivista, possibilita-se agregar os sujeitos aos processos mentais, gerando representações que sejam socialmente plausíveis (ZURLO, 2004). Nessa lógica, o processo do design estratégico evolui da tomada de decisão (decision making) para a construção de sentido (sensemaking) (WEICK,1997).

A capacidade de mediação é outro aspecto presente na atividade de design estratégico, uma vez que o designer torna-se mediador entre dimensões imateriais (imagens e ideias) e materiais (artefatos físicos), afirma Krucken (2009), assim como articula os diferentes atores envolvidos no processo colaborativo (pessoas, organizações e stakeholders). Observa-se também a mudança no papel do designer nos negócios e na sociedade, aponta Muratovski (2015). Nos últimos anos, com o expansivo movimento da manufatura para o Leste, o Oeste orientou seu 
desenvolvimento para uma economia baseada no conhecimento, com modelos focados em serviços e tecnologia. Nessa circunstância, surge a figura do designer corporativo (MURATOVSKI, 2015), que articula metodologias, conhecimento técnico e habilidades criativas frente a demandas mais espontâneas e em tempo real (online), podendo trabalhar sob demanda de acordo com os movimentos desses diferentes contextos.

Além disso, a prática do codesign é uma característica presente em alguns processos do design estratégico e que pode gerar benefícios à medida que permite criar uma linguagem comum e estratégias compartilhadas. "Para que os projetos gerem cenários adaptáveis a futuras mudanças de composições sociais, eles devem contar com o conhecimento compartilhado e a criatividade social" (MERONI, 2008). Dessa maneira, a atividade que estimula a participação colaborativa de diferentes atores (pessoas, organizações e stakeholders) terá enriquecido suas probabilidades de formular e implementar soluções. Por outro lado, Manzini (2015) compreende o codesign em um sentido mais abrangente: "um amplo e multifacetado diálogo entre indivíduos e grupos que iniciam atividades de design nos nós das redes das quais fazem parte: um diálogo social no qual diferentes atores interagem de diferentes maneiras e em diferentes momentos". Para o autor, o codesign é um processo altamente dinâmico, por vezes complexo, que pode conduzir a consenso ou contradição. Pode ou não ser composto de designers, os quais, nesse caso, atuam como criativos e facilitadores de ideias entre outros participantes, desencadeando o diálogo social e novas ideias.

O design estratégico também pode agir com o intuito de impulsionar inovações. A inovação ocorre quando se alcança um resultado de ruptura pontual que causa a evolução de um sistema (empresa, negócio ou aspecto social), ao invés de apenas seu desenvolvimento (MERONI, 2008). Há diferentes níveis de inovação: a incremental, que traz melhorias em aspectos funcionais, e a radical, que pressupõe a disrupção de conceito, ao gerar uma nova percepção de significado a um produto ou serviço. Conforme Ouden (2012), a inovação significativa deve gerar propostas de valor que beneficiem não apenas os usuários, mas também as organizações, os ecossistemas e a sociedade como um todo. Quando ocorre uma transformação sociotécnica impulsionada por e orientada à mudança social, ela pode configurar a inovação social (MANZINI, 2015).

A partir desse panorama geral a respeito da atuação do designer estratégico, percebe-se que suas capacidades adquiridas o atribuem um imenso potencial de compreensão, criação e modificação de contextos. Suas habilidades técnico-projetuais, aliadas à compreensão das possíveis implicações que o uso de artefatos, serviços e tecnologias podem causar à sociedade, se utilizadas com responsabilidade, coerência e, principalmente, um propósito bem definido, podem alavancar repercussões na malha social.

Pela lógica metaprojetual aplicada ao design (BENTZ E FRANZATO, 2016), o designer não deve limitar-se à atuação em campo projetual. Sua capacidade crítico-reflexiva deve preceder e orientar essa etapa, em uma atuação recursiva nos níveis de conhecimento do design, na qual reflexões conduzem à otimização de processos projetuais, e seus resultados repercutem em contribuições a aportes metodológicos. Em movimentos de deslocamento heurístico máximo, as explorações metodológicas do design possibilitam 0 surgimento de novas diretrizes epistemológicas ao campo do conhecimento.

Sendo assim, com base nos princípios metaprojetuais, provoca-se a reflexão a respeito da atual contribuição do designer estratégico na sociedade a partir da efetiva introjeção e prática de 
suas capacidades. Por um lado, é notável a falência do sistema político-econômico na configuração de um ecossistema sociotécnico sustentável e adequado às novas dinâmicas e necessidades da sociedade. Por outro, é iminente o potencial de contribuição do design à sociedade, capaz de atuar na tensão de interesses entre atores ecossistêmicos e alavancar soluções criativas capacidade intrínseca deste profissional - sem, contudo, ser reduzido a nível técnico projetual.

Ademais, qual o propósito que rege a atuação do designer estratégico? Sua reputação no mercado? O lucro de seu cliente? O benefício das implicações de seu projeto ao usuário? O bemestar social? Para quem se projeta: para o cliente, para o usuário, ou para si mesmo? Analisando as habilidades e capacidades deste profissional, aqui resumidas, parece faltar um regimento de significado, um propósito maior e consensual que oriente a prática comum e assim a torne explicitamente reconhecida pela sociedade. O objetivo deste artigo não é buscar respostas para os questionamentos acima, e, sim, utilizá-los como motivação para a geração do cenário a seguir.

\section{Cenário design-orienting: O Designer Estratégico Como Operador Social}

A partir do repertório apresentado, propõe-se um cenário design-orienting (DOS) nos parâmetros do papel e contribuição do designer na sociedade futura. Sua visualização se dá em um contexto que tangencia o designer em seu processo de atuação, assim como os atores envolvidos no mesmo. No cenário descrito a seguir, todas as situações são hipotéticas.

\subsection{Visão}

Como seria o mundo se o designer fosse denominado um operador social - ator que orienta soluções criativas dentro de ecossistemas colaborativos com o principal propósito de contribuir para o bem-estar social? Como seriam os artefatos, serviços e tecnologias se seu desenvolvimento fosse pautado essencialmente pelos seus potenciais benefícios à sociedade, e orientado pelos princípios da ética, da responsabilidade social e da sustentabilidade? E os briefings, como seriam se o designer só os executasse a partir dessas premissas? Quanto às estratégias organizacionais, como seriam elas se o ecossistema sociotécnico compreendesse o designer como um ator essencial à sobrevivência de uma organização? No sentido denominativo, como seria se o designer só pudesse atuar mediante a aquisição das capacidades do designer estratégico e do operador social?

A lógica de operador referencia Manzini (1992): "Considerado como um operador que atua em relação ao ambiente diário, a responsabilidade final do designer só pode ser contribuir para a produção de um mundo habitável,...". No contexto imaginado, entretanto, o designer deixa de agir e ser compreendido (apenas) como um operador técnico-projetual, passando a ser reconhecido, principalmente, por sua capacidade de atuação como um agente de mudança social. Munido dessa distinção e responsabilidade, o designer agrega a ação metaprojetual como ponto de partida a qualquer contexto que demanda solução, com o principal intuito de exercer sua visão crítico-reflexivo como mediadora entre as possiblidades projetuais e as necessidades sociais. Em decorrência dessa prática e reconhecimento, passa a ser chamado de operador social - ator que atua, essencialmente, a partir da ótica social, podendo, quando necessário, desempenhar sua capacidade criativa ao orientar projetistas especialistas na ação projetual.

Com a introjeção desse parâmetro como propósito de atuação profissional, naturalmente a ação projetual de artefatos, serviços e tecnologias é pautada, desde o levantamento de sua necessidade até o briefing, por um senso reflexivo maior que o aplicado anteriormente. De nada 
adianta solicitar o projeto de um artefato cujo principal objetivo é gerar vendas por impulso, ou de uma tecnologia que afasta o indivíduo de seu circuito social. Toda a ação projetual tem como pressuposto as consequências da experiência gerada ao usuário. Para tanto, o designer age de acordo com um regimento de ética, responsabilidade social e sustentabilidade, atualizado pelos atores de seu ecossistema colaborativo e que tem como propósito maior, igualmente, beneficiar a sociedade e provê-la com estímulos ao seu bem-estar.

Nesse momento, as organizações compreendem a necessidade de atuarem com, ao menos, um designer em suas equipes, já que seus parâmetros conjugam os conhecimentos e capacidades multidisciplinares necessários para atender às novas demandas do ecossistema sociotécnico. Sistema esse pautado por atores diversos que vêm a ser os usuários das ofertas das organizações. Dessa maneira, seus esforços são orientados por e para a malha social.

O designer, por sua vez, ao avançar no campo do conhecimento e assumir a capacidade de operador social como principal propósito, desprende-se do vínculo técnico-projetual, utilizando-o apenas como repertório que orienta projetistas especializados. Nesse contexto, o denominativo estratégico passa a ser omitido, pois é pressuposto subentendido na atuação do designer, já que não existe prática do design sem ação metaprojetual. Assim, o profissional configura-se, legitimamente, como designer operador social.

\subsection{Motivação}

O design, por seu aspecto técnico, possibilita um ciclo infinito de desenvolvimento de artefatos. Não há um regimento de parâmetros ético- sustentável que oriente a ação desenfreada da produção em massa, a não ser a sua não aceitação pela sociedade. Manzini (1992) alerta para a falta de uma cultura do design capaz de confrontar as novas possibilidades tecnológicas, fato que resultou em uma disseminação de artefatos inúteis e prejudiciais ao meio ambiente. Dessa maneira, grande parte do potencial da tecnologia está desperdiçado em produtos descartáveis e artefatos efêmeros desprovidos de significado cultural, gerando à sociedade (seus usuários) um senso de superficialidade. Outro aspecto a ser considerado é o prejuízo dessa prática à semiosfera, ou seja, a poluição semiótica a nós causada pelo aumento da massa de informação (MANZINI, 1992).

Percebe-se, entretanto, um movimento contrário à cultura do consumo sem propósito estabelecida principalmente na sociedade ocidental -, que busca, por meio da atuação de diferentes atores de ecossistemas criativos e colaborativos, novas soluções orientadas pela inovação social e sustentabilidade. Essas práticas emergem, como citado inicialmente, de abordagens do design que têm como ponto de partida o contexto social, o qual orienta as ações estratégica e projetual, fazendo do projeto uma consequência da prática crítico-reflexiva do design. Dessa maneira, o design migra do âmbito projetual e influencia as dinâmicas da malha social por meio de projetos que carregam propósitos bem definidos.

Manzini (1992) aproxima o diálogo entre o design e os contextos sociais ao afirmar que as problemáticas sociais podem gerar um vasto horizonte para o design, tornando-se a fonte de uma série de transformações culturais e de práticas sociais contemporâneas. O autor motiva a geração de cenários que considerem os problemas sociais emergentes e os articule em referência à atividade do designer: "Nós carecemos de uma ética do design adequada à nova estrutura problemático e a novas sensibilidades". 
Sendo assim, grande parte das motivações para a concepção deste cenário encontra-se na dialogia entre as consequências e potenciais das práticas da profissão confrontados na atualidade. Além disso, as investigações metaprojetuais aplicadas a contextos de design são possibilidades enriquecedoras ao campo do conhecimento. Entretanto, por mais que a literatura registre diversas abordagens calcadas nas contribuições sociais do design, há poucos exercícios de elaboração de cenários respectivos.

\subsection{Propostas}

A partir das visões apresentadas, derivam-se três principais conceitos para o cenário. Eles se estabelecem com o intuito de provocar reflexão no campo do design. Por suas propostas estarem relacionadas a parâmetros correlatos aos processos de design, o cenário configura-se como design-orienting (DOS).

\subsubsection{Do Designer ao Designer Estratégico}

A compreensão sobre o termo designer amplia-se. Um designer, nesse momento, não mais limita-se a atuar como um operador projetual. Este, será intitulado projetista especialista, de acordo com seus domínios técnicos. O profissional designer passa a atuar, invariavelmente, com a as capacidades e habilidades de um designer estratégico. Nesse contexto, o designer não necessita mais operar em nível projetual, mas precisa dominar essa prática para orientar a execução por parte do projetista especialista.

Nesse momento, o designer atua essencialmente no campo metaprojetual, orientado pelas habilidades de reformulação do problema, do domínio e transformação de contextos, do codesign, da articulação ecossistêmica e da abertura para inovação. Solicitar o serviço de um designer pressupõe não mais a entrega de um projeto técnico, e sim de conteúdo estratégico.

Ao operar o design como designer estratégico, trabalha-se em nível metaprojetual. Isto é, todos os processos são permanentemente orientados pela reflexão e crítica - tanto o projetual, considerando as implicações do método aos resultados do projeto, quanto o metodológico, analisando as contribuições da prática para a melhoria dos métodos. O desempenho recursivo nos níveis de conhecimento ao design colocam esta atividade em constante evolução.

\subsubsection{O Designer Como Operador Social}

Aos poucos, o designer e seu ecossistema de atuação percebem o potencial da profissão para a resolução de problemas sociais. A tecnologia impõe mudanças dinâmicas à sociedade, das quais decorrem novas necessidades sociotécnicas que a estrutura do sistema político-econômico não é mais capaz de sustentar. É necessário reinventar as profissões e, principalmente, repensar o papel dos atores na reestruturação das dinâmicas sociais.

Nesse momento, o designer - que já opera essencialmente de forma estratégica reformula o seu papel através de uma visão metaprojetual: as implicações sociais causadas pela sua atuação tornam-se o principal propósito do design. O designer passa, então, a denominar-se um operador social. Suas práticas e processos são norteados, primeiramente, pelo interesse pelo bem-estar da sociedade como um todo, a partir da compreensão de que o coletivo é composto por necessidades individuais. Compreende-se que o bem-estar é correlato à sustentabilidade, e sua responsabilidade envolve a capacitação da sociedade para que a mesma possa, de forma autônoma, exercitar suas próprias habilidades nesse caminho. 
Ao compreender os benefícios que o designer operador social causa às suas dinâmicas, a sociedade o reconhece como um ator de relevância para o seu desenvolvimento. Em compensação, atua como membro dos ecossistemas criativos e colaborativos orientados pelos designers, gerando empatia e troca de conhecimento transdisciplinar entre os atores envolvidos. As ações individuais são orientadas para o bem-estar coletivo.

\subsubsection{O Designer nas Organizações}

Estabelecida a relação de confiança entre o designer operador social e os indivíduos da sociedade, o resto do ecossistema inicia sua aderência à compreensão sobre esse profissional. A tecnologia configura novos formatos de trabalho e indica a redução do número de profissionais vinculados às organizações. As relações organizacionais tornam-se líquidas, remotas e complexas, mas sua conexão em rede permite inúmeros modelos de trabalho colaborativo.

O designer operador social torna-se um ator fundamental frente à complexidade dos novos contextos organizacionais. Ele estabelece diretrizes que organizam e norteiam os processos internos nas intenções da organização quanto ao seu papel social. O designer atua, então, na formulação e reformulação dessas operações, tendo como fundamento seus princípios ético e sustentável. Quando necessária a ação projetual técnica, o designer define projetistas especialistas que possam executar as tarefas de acordo com os princípios da operação social.

\section{Considerações Finais}

Apesar das abordagens emergentes que posicionam o designer como agente de mudança, o design ainda é uma atividade prevalentemente percebida por suas habilidades técnicoprojetuais. Por esse motivo, o principal objetivo deste artigo foi o de confrontar alguns contextos de atuação já existentes com um cenário hipotético orientado para uma ótica que repercute mundialmente: o papel das profissões na construção de um mundo mais habitável.

Alguns pesquisadores, como Manzini (2015), que representa os percursos da inovação social, e Tromp (2013), que propõe o método SID - Social Implication Design no caminho para a mudança social influenciada pelo design, são exemplos de esforços capazes de motivar novas visualizações para o papel do designer na sociedade. Suas pesquisas e novas investigações devem ser cultivadas e estimuladas, especialmente pela abordagem metaprojetual, para a evolução prático-teórica do campo do design.

\section{Referências}

BENTZ, lone; FRANZATO, Carlo. O Metaprojeto nos Níveis do Design. Blucher Design Proceedings, v. 2, n. 9, p. 1416-1428, 2016.

BRUNO, Latour. Where Are the Missing Masses? The Sociology of a Few Mundane Artefacts'. 1992.

DUNNE, Anthony. Hertzian tales: Electronic products, aesthetic experience, and critical design. 2008.

FRANZATO, Carlo. O princípio de deslocamento na base do metadesign. In: 11 o Congresso Brasileiro de Pesquisa e Desenvolvimento em Design. 2014. p. 1187-1196.

KRIPPENDORFF, Klaus. The semantic turn: A new foundation for design. crc Press, 2005.

KRUCKEN, Lia. Design e território: valorização de identidades e produtos locais. São Paulo: Studio 
Nobel, 2009. P.41-70.

MANZINI, Ezio; CULLARS, John. Prometheus of the Everyday: The Ecology of the Artificial and the Designer's Responsibility. Design Issues, v. 9, n. 1, p. 5-20, 1992.

MANZINI, Ezio. Design, when everybody designs: An introduction to design for social innovation. MIT press, 2015.

MANZINI, Ezio; JÉGOU, François. Design dos cenários. In: BERTOLA, P.; MANZINI, E. Design Multiverso | Notas de fenomenologia do design. Milano: Edizioni POLI.design, 2006, pp. 189-207.

MERONI, Anna. Strategic design: where are we now? Reflection around the foundations of a recente discipline. Strategic Design Research Journal, v.1, n.1, Dec 1, p.31-38. 2008.

MORIN, Edgar. O método 3. O conhecimento do conhecimento. Porto Alegre: Sulina, 1999.

MURATOVSKI, Gjoko. Paradign Shift: Report on the New Role of Design in Business and Society. She Ji: The Journal of Design, Economics, and Innovation, v.1, n. 2, p.118-139. 2015.

OUDEN, Elke den. Meaningful Innovation. Innovation Design. Springer, 2012. 196 p. ISBN-13 9781447122678.

SHOVE, Elizabeth et al. The design of everyday life. Berg. 2007.

TROMP, Nynke. Social Design: How products and services can help us act in ways that benefit society. 2013.

VERBEEK, Peter-Paul. Moralizing technology: Understanding and designing the morality of things. University of Chicago Press, 2011.

WEICK, Karl. Sensemaking in Organizations. London. 1995.

ZURLO, Francesco. Design Strategico. In: XXI Secolo, vol. IV, Gli spazi e le arti. Roma: Enciclopedia Treccani. 2010. 